\title{
ANÁLISE DAS EMOÇÕES NA VIDA ACADÊMICA: CONHECENDO E COMPREENDENDO
}

\author{
ANALISIS DE LAS EMOCIONES EN LA VIDA ACADÉMICA: \\ CONOCIENDO Y COMPRENDIENDO
}

\begin{abstract}
ANALYSIS OF THE EMOTIONS IN ACADEMIC LIFE: KNOWING AND UNDERSTANDING
\end{abstract}

\begin{abstract}
Otávio Paulino Lavor ${ }^{1}$
Mônica Paula de Sousa Martins"

${ }^{\text {I } U n i v e r s i d a d e ~ F e d e r a l ~ R u r a l ~ d o ~ S e m i-a ́ r i d o ~(U F E R S A), ~ P a u ~ d o s ~ F e r r o s / R N-B r a s i l ~}$

II Universidade Federal Rural do Semi-árido (UFERSA), Pau dos Ferros/RN-Brasil
\end{abstract}

ReSumo As emoções podem ser refletidas em gestos e ações que determinam as fases cruciais no comportamento humano. Um ambiente emocional frágil pode interferir diretamente no rendimento de uma atividade que exija habilidades específicas e concentração. O presente trabalho busca quantificar e compreender o grau de identificação discente em relação às emoções, bem como, verificar se o ambiente emocional compromete o rendimento acadêmico e se há um anseio por interferência de líderes capacitados. Para atender ao objetivo, foi feito um levantamento por meio de questionários aplicados em uma instituição de ensino superior na região do Alto Oeste Potiguar. As respostas conduzem ao fato de que os discentes, embora conheçam suas emoções e identifiquem as emoções dos seus colegas, julgam que o rendimento acadêmico é diretamente afetado por questões emocionais e aguardam uma parceria comunicativa e adequada dos líderes envolvidos a fim de possibilitar diálogos e intervenções nos problemas emocionais, para que os resultados acadêmicos sejam satisfatórios.

Palavras-chave: Educação superior; Contexto social; Vida do Educando; ComuNICAÇÃO E EDUCAÇÃO.

ABSTRACT Emotions can be reflected in gestures and actions that determine the crucial phases in human behavior. An emotional environment can directly interfere with the performance of an activity that requires specififs habilitys and concentrate. The present work seeks to quantify and understand the degree of identificattion in relation to the emotions, as well, as to verify if the emotional environment compromises the academic performance 
and if there is a wish by interference of trained leaders. To reach the objective, a survey was carried out by means of questionnaires applied to a higher education institution in the region of the Alto Oeste Potiguar. The answers lead to the fact that, although they know their emotions and identify those of their colleagues, they believe that academic achievement is directly affected by emotional issues, and they expect a communicative and adequate partnership of the leaders involved in order to enable dialogues and interventions in the problems so that the academic results are satisfactory.

Keywords: College education; Social context; Educando's life; Communication AND EDUCATION.

RESUMEN Las emociones pueden ser reflejadas en gestos y acciones que determinan las fases cruciales en el comportamiento humano. Un ambiente emocional frágil puede interferir directamente en el rendimiento de una actividad que exija habilidades específicas. El presente trabajo busca cuantificar y comprender el grado de marcaje discente en relación a las emociones, así como, verificar si el ambiente emocional compromete el rendimiento académico y sí hay un anhelo por interferencia de líderes capacitados. Para atender el objetivo, se efectuó un levantamiento por medio de cuestionarios aplicados en una institución de enseñanza superior en la región del Alto Oeste Potiguar. Las respuestas conducen al hecho de que los discentes, aunque conocen sus emociones e identifican a emociones de sus colegas, juzgan que el rendimiento académico es directamente afectado por cuestiones emocionales y aguardan una asociación comunicativa y adecuada de los líderes involucrados, a fin de posibilitar diálogos e intervenciones en los mismos problemas emocionales para que los resultados académicos sean satisfactorios.

Palabras clave: Educación universitaria; Contexto social; Vida del Educando; COMUNICACIÓN Y EDUCACIÓN.

\section{INTRODUÇÃo}

A universidade é composta por diversos públicos que carregam suas histórias e suas emoções e que estão reunidos prevendo um fortalecimento de conhecimento em uma área específica visando satisfazer exigências de um mercado para conseguir serem contratados. Tais exigências são satisfeitas após uma série de dificuldades e desafios que cada cidadão que sonha compor os quadros de uma empresa ou instituição, que requeira nível superior, enfrenta. Isso, por que, considerando, como Miguel, Finoto e Miras (2013), mesmo que "capacidades cognitivas e traços de personalidades sejam independentes, (...) No nível individual, pode ser possível encontrar relação entre os construtos, dependendo do histórico de vida de cada um".

As dificuldades e desafios estão presentes em todo o percurso de estudante, tornando-o um sujeito emocionalmente vulnerável, como destacam Tomás et al. (2014) lembrando que "a adaptação ao ensino superior tem sido amplamente estudada, dadas as dificuldades vivenciadas por uma percentagem significativa de estudantes, e que resultam em insucesso escolar e abandono". Observando tais fragilidades no ensino superior, viu-se a necessidade de olhar para a universidade como um campo de emoções. 
Bzuneck (2009) afirma que, à medida que os alunos avançam no nível de ensino, o interesse tende a decair e as dúvidas quanto à própria capacidade de aprender se inclinam a aumentar. Então, a experiência docente em cursos da área de Ciências e Tecnologia trouxe uma reflexão em torno dessa necessidade de relacionar rendimento acadêmico a ambientes emocionais dos discentes com o objetivo de desenvolver a motivação dos mesmos por meio de diálogos, usando como justificativa a importância dos conhecimentos desenvolvidos para o futuro bem-estar profissional e pessoal.

Segundo Souza et al. (2019), a motivação para aprender é objeto de estudo de diversas áreas do conhecimento, pois está relacionada com a aprendizagem escolar. E isso enfatizou a percepção de que a motivação é uma atividade pessoal e uma ou outra prática metodológica se diferencia pela percepção emocional de cada discente. Essa capacidade de regular em si e expressar para os outros o quanto uma ou outra situação de vida impulsiona ou não $o$ ato de se envolver em uma atividade de aprendizagem parece influenciar no rendimento acadêmico, rompendo as barreiras das frustrações e impulsionando para satisfazer as exigências do curso e do futuro profissional.

Estes seriam os objetivos específicos desta pesquisa, visando de forma geral exibir uma análise estatística das percepções emocionais no contexto acadêmico de cursos de Ciência e Tecnologia, com a finalidade de disponibilizar uma contextualização de mais essa variável que subjaz o melhoramento do rendimento acadêmico discente.

\section{REVISÃO DA LITERATURA}

Considerando que a motivação é uma atividade pessoal, o ato de se envolver em uma atividade de ensino depende da avaliação que cada discente faz sobre ser um evento significativo. Por exemplo, uma atividade de pesquisa que envolve aplicações gera entusiasmos para uns pelo fato de colocá-los diante de um possível futuro profissional, já para outros causa medo, pois focaliza-se a necessidade de mais conhecimentos. Lidar com essa significação parece o diferencial. E a percepção emocional seria uma variável a se investigar, já que "emoção é um processo emergente e dinâmico que tem como base uma avaliação subjetiva de eventos significativos" (SCHERER, 2009, apud BZUNECK, 2018) e tem importância nas operações mentais, uma vez que:

1) a emoção torna o pensamento mais inteligente; 2) a inteligência cognitiva auxilia o indivíduo a pensar as suas emoções e as dos outros; 3 ) a ausência dessa relação binomial torna o indivíduo emocional e socialmente incapaz (MAYER; SALOVEY, 1997, apud FRANCO; SANTOS, 2015, p. 339).

A postura dos líderes e agentes acadêmicos, entre eles o docente, ao aprimorarem essa capacidade de identificação de emoções, acrescentaria ao meio acadêmico mais uma ferramenta para trabalhar as especificidades de cada situação, considerando que:

...emoções se revelam em expressões motoras, facilmente identificáveis, por exemplo, nas emoções da raiva ou de medo, e têm potencial para ação. Quanto à valência, temos emoções positivas ou negativas, sendo que ambas variam em intensidade, duração e especificidade situacional (BZUNECK, 2018, p. 1.060). 
Assim, desenvolver essa percepção emocional possivelmente permitiria identificar aquelas que são próprias do contexto acadêmico, diferenciando das interpessoais, por exemplo. Permitiria avaliar se essa identificação e uma mudança de postura por parte dos agentes acadêmicos minimizariam a influência das mesmas no rendimento dos discentes, já que uma prova pode provocar tanto emoções positivas como satisfação, orgulho, esperança, alívio, quanto emoções negativas como ansiedade, medo, desesperança, vergonha e tédio (AHMED et al., 2013; MEGA; RONCONI; DEBENI, 2014; PEKRUN et al., 2011, apud BZUNECK, 2018).

Cabe então quantificar, diante da percepção discente, se a intervenção dos líderes e agentes acadêmicos, como o docente, auxiliaria no processo intrapessoal do qual surgem as emoções, ou seja, no desenvolvimento das habilidades necessárias a expressar-se adequadamente, interpretá-las e regulá-las, adquirindo, como agruparam Denham et al. (2003), apud Franco e Santos (2015), em componentes, expressão emocional, regulação emocional e compreensão das emoções.

Dessa forma, conhecer que as emoções resultam tanto dos eventos quanto das especificidades que se dá a eles possivelmente permitiria organizar previamente os ânimos dos discentes para ambas as situações, creditando o sucesso ao empenho, por exemplo, sem atribuir os fracassos à falta do mesmo. Identificando as irritações, como quando avaliam que uma prova esteja extremamente difícil, atribuindo a fatores incontroláveis e externos ou a fatores internos não controláveis, como falta de capacidade. E observando cada emoção num viés motivacional, tendo empatia e utilizando o potencial de superação inerente a cada uma delas, uma vez que, concordando com Pekrun (2006) citado por Bzuneck (2018), há um duplo julgamento por parte dos discentes de controle e valorização, quando aquele:

...refere-se à expectativa de que, com seu esforço e persistência, terá resul-
tados positivos. Mas refere-se também a controle sobre o próprio agir, que é
um conceito compatível com o de autoeficácia. Já valorização corresponde à
percepção de que o resultado à vista tem importância pessoal (BZUNECK,
2018 , p. 1.061).

A partir disso, a percepção emocional por parte do discente parece também norteadora para superação das dificuldades inerentes ao contexto acadêmico, como as advindas do Ensino Médio, por exemplo, em disciplinas matemáticas, uma vez que perceber os problemas que geram uma ou outra emoção possibilita uma autorregulação de sua aprendizagem, pois se passa a buscar emoções positivas a cada superação, e estas "tendem a expandir o repertório de ações derivadas de pensamentos, isto é, elas abrem a mente e, assim, desafios são enfrentados com mais disposição" (BZUNECK, 2018, p. 1.062).

Percebe-se então que as emoções subjazem ao contexto do processo de aprendizagem e motivação para a aquisição de conhecimentos, e aquela tidas como negativas são inevitáveis se for considerado como um desenvolvimento cognitivo. Com isso, seria interessante buscar a percepção do discente sobre a relação das emoções com o rendimento acadêmico, uma vez que a inteligência ajuda o indivíduo a pensar suas emoções (FRANCO; SANTOS, 2015), combatendo o sentimento de vergonha com a crença de autoeficácia, o tédio com a autopromoção de interesse ou a ansiedade com outro diálogo interno construtivo, substi- 
tuindo o destrutivo (BZUNECK, 2018). Em outras palavras, usando inteligência emocional, pois esta foi definida como:

\begin{abstract}
...a capacidade de empregar o raciocínio sobre as emoções, ou seja, ter percepções objetivas, saber compreender, expressar e avaliar os sentimentos ou reações emocionais de forma coerente e de maneira adaptada à situação. (MIGUEL; FINOTO; MIRAS, 2013, p. 108).
\end{abstract}

Assim, uma pesquisa quantitativa da compreensão dos discentes frente à percepção emocional com o auxílio de líderes acadêmicos que desenvolvessem essa capacidade forneceria dados para se interpretar a regulação das emoções, permitindo avanços da teoria social cognitiva nos estudos sobre as emoções na educação e contribuindo para saúde mental dos discentes.

Não havendo, na presente pesquisa, a intenção de fornecer mensuração da inteligência emocional dos discentes, tão menos uma análise das características psicométricas de algum teste psicológico (MIGUEL; FINOTO; MIRAS, 2013), mas sim levantar a relevância que os mesmos dão a se trabalhar essa percepção emocional em si e nos líderes dentro da academia como alternativa de melhoria no rendimento acadêmico, de onde se teria traços do que os mesmos acreditam e se empenhariam a trabalhar, pois como se destaca, pesquisas demonstram que:

\begin{abstract}
...quando se mede inteligência emocional por meio de um instrumento de autorrelato como um inventário, encontra-se correlações significativamente elevadas com traços de personalidade e poucas com outras medidas de raciocínio (MIGUEL; FINOTO; MIRAS, 2013, p. 109).
\end{abstract}

Com isso, o questionário aplicado aos discente e discutido neste artigo intenciona destacar os traços de personalidade relacionados à concepção de percepção emocional dos mesmos diante de si e de seus líderes acadêmicos, servindo também para comprovar as divergências com alguma avaliação de inteligência emocional por meio de instrumentos de desempenho, já que, como destacam Miguel, Finoto, e Miras (2013), a relação dessas avaliações com traços de personalidade costuma ser baixa ou quase nula.

Além disso, destacaria a importância de os líderes desenvolverem essa capacidade com a finalidade de melhorem suas habilidades sociais, aqui entendidas como condutas específicas responsáveis pela aceitação e rejeição em uma coletividade, já que ler as mensagens não verbais enviadas pelos outros permite entender os aspectos emocionais e detalhar melhor o significado de cada mensagem (SENA et al., 2018). Levando, em particular o docente, como destacam Abe et al. (2013) citado por Sena et al. (2018), "a proceder de uma observação mais profunda e significativa e, com isso, ele poderá perceber ocasiões e ocorrência que levam os indivíduos a demandar de maior apoio técnico".

Portanto, este artigo apresenta uma pesquisa-ação envolvendo uma amostra de 65 discentes de um curso de Ciências e Tecnologia, cuja metodologia consistiu em aplicar um questionário e analisá-lo quantitativamente para fornecer dados úteis à regulação das emoções à luz da Teoria Social Cognitiva (BZUNECK, 2018), diminuir a escassez de estudos científicos ligados à inteligência emocional (SILVA; SILVA, 2018), bem como, para verificar sua influência na aprendizagem e bem-estar dos discentes, já que: 
As emoções positivas, como as negativas afetam todos os nossos processos mentais, desde a atenção, até processos intelectuais e cognitivos mais complexos, contribuindo ou prejudicando para o aprendizado (CHABOR; CHABOAT, 2015, apud SILVA; SILVA, 2018, p. 20).

Observando, assim, se a capacidade de percepção emocional no discente e nos líderes acadêmicos melhoraria o apoio necessário ao bem-estar mental durante o andamento de um curso de graduação, uma vez que se teria uma "via de mão dupla" em uma das funções das emoções que é a de "comunicar a condição interna da pessoa aos outros e provocar uma resposta, orientando e regulando o comportamento" (PAPALIA, 2006, apud SILVA; SILVA, 2018), isto é, produzindo empatia e talvez diminuindo os relatos de pressão na vida acadêmica.

Relatos esses que não têm um conjunto gerador de fatores limitado, mas perpassam desde o crescimento intelectual do discente até o social, incluindo o estabelecimento de relações positivas com os pares e docentes, o que reforça a capacidade de percepção emocional como uma variável importante no rendimento acadêmico e destaca, como o fazem Tomás et al. (2014), que:

O processo de adaptação ao ensino superior requer a ativação de competências adaptativas a um novo contexto, a mobilização de recursos pessoais e contextuais para o enfrentamento dos desafios emocionais, académicos, sociais e institucionais, assim como o desenvolvimento de novas estruturas de funcionamento pessoal e interpessoal (TOMÁS et al., 2014, p. 89).

Assim, as questões levantadas aos discentes pesquisados levam também a observar se o enfrentamento dos desafios emocionais é mais fácil quando se tem líderes acadêmicos que desenvolvem essa capacidade de percepção emocional como descritas por Sena et al. (2018) no proceder de observações mais profundas do agir dos discentes. Permitindo, assim, que tais líderes refletissem se o discente se desenvolve integrando, controlando, reconhecendo e canalizando as emoções de forma equilibrada, se não há um alto nível de estresse, depressão, solidão e saudades de casa, se há envolvimento em tarefas acadêmicas e extracurriculares ou compromisso com a persistência, ou seja, se o discente consegue gerir suas emoções e as dos outros, do mesmo modo que os docentes e os demais líderes (TOMÁS et al., 2014).

Levando, com isso, a crer que o presente trabalho contribui para verificar a importância da percepção emocional, subjacente à inteligência emocional, para o sucesso e bem-estar acadêmico dos discentes, uma vez que "a habilidade para perceber as emoções é um preditor estável de um menor desajuste clínico e emocional, assim como de um maior ajuste pessoal" (PALOMERA; SALGUERO; RUIZ-ARANDA, 2012, apud TOMÁS et al., 2014).

Como o estudo procura estabelecer relação entre a emoção e o rendimento acadêmico, os líderes têm um papel crucial nesse processo. Então faz-se necessário conceituar liderança e enfatizar seu papel na atividade desenvolvida.

O líder tem um papel fundamental no direcionamento de soluções, visto que: 
...podemos definir liderança como a uma influência interpessoal exercida numa situação dirigida através do processo de comunicação humana com objetivos específicos. Os elementos que caracterizam a liderança são, portanto, quatro: a influência, a situação, o processo de comunicação e os objetivos a alcançar (CHIAVENATO, 2005, p. 558).

Diante disso, pode-se dizer que a atividade de liderança passa pelo processo de comunicação que influenciará diretamente nas emoções da situação e das exigências apresentadas.

De acordo com Carvalho, Bertol e Alberton (1998), a liderança pode ser definida como um processo de influenciar as atividades de indivíduos ou grupos para consecução de um objetivo, numa dada situação. Consiste no exercício contínuo de relações interpessoais dentro de uma dinâmica organizacional, em que se despontam todos os valores humanos de todos os envolvidos no processo.

A liderança é um assunto estudado por diversas áreas do conhecimento devido a sua influência sobre o pensamento e comportamento de outras pessoas (CASSIMIRO; FONTELES; FARIAS, 2013). Assim, a atividade de liderança passa também pelos anseios acadêmicos nas diversas áreas de formação.

Lameiras (2010) diz que a liderança possui um papel relevante nas organizações, muitas vezes sendo confundida com a própria gestão. Hersey e Blanchard (1986) afirmam que a administração pode ser considerada como uma forma especial de liderança, voltada para o alcance dos objetivos organizacionais. Então, o conceito de liderança é mais abrangente em função de também englobar aspectos pessoais e do cotidiano dos indivíduos.

Como entende-se que a emoção é um aspecto pessoal e do cotidiano dos estudantes, surge o anseio por um estudo que viabilize uma motivação discente a partir da percepção emocional de um líder comunicativo que aja de forma adequada.

\section{Metodologia}

Para análise do estudo, buscando quantificar a percepção dos discentes em relação às emoções, como o ambiente emocional se relaciona com o rendimento acadêmico e se necessita da interferência dos líderes na interpretação das mensagens não verbais enviadas pelos mesmos para entender seus aspectos emocionais, um questionário foi elaborado com perguntas objetivas com alternativas sim ou não, além de um espaço opcional para outros comentários que os discentes possam julgar pertinentes para a temática. As perguntas visavam identificar as percepções do entrevistado para que pudesse compreender a dimensão dos problemas emocionais, com a finalidade de levantar a relevância da percepção emocional dentro da realidade acadêmica, bem como, o anseio pela comunicação adequada de um líder.

O público-alvo são discentes do ensino superior em uma universidade localizada na região do Alto Oeste Potiguar. Foi tomada uma amostra de 65 discentes de forma aleatória para responder ao questionário. Sabendo-se que o Campus da Universidade possui 1.311 discentes ativos, a quantidade foi tomada levando em consideração uma confiabilidade de $90 \%$ com base na fórmula a seguir: 


$$
\text { Tamanho da amostra }=\frac{\frac{Z^{2} p(1-p)}{e^{2}}}{1+\left(\frac{Z^{2} p(1-p)}{e^{2} N}\right)}
$$

em que $Z$ é o valor tabelado na distribuição normal de probabilidade que depende do grau de confiança, $p$ é o percentual de confiança, $e$ é o erro e $N$ é o tamanho da população.

A aplicação foi de forma voluntária e sem identificação do discente que tinha tempo livre para responder às questões, pois não se pretendia limitar suas habilidades sociais, condutas essas responsáveis pela aceitação em uma coletividade, quase sempre restringidas pelos medos de possíveis rótulos adquiridos quando seus aspectos emocionais são expostos. As questões são descritas na Tabela 1 e levam em consideração a percepção emocional como constructo subjacente à interpretação de como as emoções afetam nossos processos mentais, contribuindo ou prejudicando o rendimento acadêmico, bem como, um ambiente emocional frágil pode interferir no mesmo e um bom líder pode influenciar na tomada de decisões para chegar a soluções.

Tabela 1. Questionário

\begin{tabular}{cl}
\hline Questão & \multicolumn{1}{c}{ Pergunta } \\
\hline 01 & Você considera que consegue identificar as suas emoções? \\
02 & Você consegue identificar os problemas e soluções que movem as suas emoções? \\
03 & Você consegue identificar as emoções nas pessoas que estão ao seu redor? \\
04 & $\begin{array}{l}\text { Você acha que expressar as emoções de forma adequada pode contribuir para que o } \\
\text { próximo possa intervir adequadamente? }\end{array}$ \\
05 & $\begin{array}{l}\text { Você acha importante que os líderes na universidade desenvolvam essa capacidade } \\
\text { para contribuir com o grupo? }\end{array}$ \\
06 & Dentro da universidade, você conhece muitas pessoas com essa característica? \\
07 & Você acha que suas emoções podem influenciar no rendimento acadêmico? \\
08 & Você gostaria que os líderes na universidade identificassem suas emoções? \\
10 & Você gostaria que os líderes se comunicassem sobre suas emoções? \\
\hline
\end{tabular}

Fonte: Autores (2019).

\section{Análise de RESUltados}

Com a hipótese de que as percepções emocionais podem influenciar o rendimento acadêmico, como destacam Chabor e Chaboat (2015), citados por Silva e Silva (2018), ao destacarem a relação das emoções positivas e negativas com a atenção, por exemplo, os questionários foram analisados. As estatísticas podem ser vistas nesta seção e a Tabela 2 mostra um resumo das mesmas para cada pergunta do questionário. 
Tabela 2. Respostas ao questionário

\begin{tabular}{ccc}
\hline Questão & Resposta Sim & Resposta Não \\
\hline 01 & 54 & 11 \\
02 & 49 & 16 \\
03 & 41 & 24 \\
04 & 57 & 08 \\
05 & 58 & 07 \\
06 & 17 & 48 \\
07 & 63 & 02 \\
08 & 46 & 19 \\
09 & 40 & 23 \\
10 & 62 & 03 \\
\hline
\end{tabular}

Fonte: Autores (2019).

Com base nas respostas da primeira pergunta, $83 \%$ dos discentes conseguem identificar as suas próprias emoções, no entanto essa porcentagem é reduzida para $75 \%$ quando a questão é identificar os problemas e soluções. Isso indica que existe uma parcela de discentes que não conseguem sozinhos avaliar seu ambiente emocional e que a ajuda de terceiros pode ser conveniente. Fato que leva à necessidade de ações que trabalhem a inteligência emocional, ajudando os discentes a pensarem suas emoções, como relatado por Franco e Santos (2015), trabalhando temas como o sentimento de vergonha, o tédio ou a ansiedade, buscando a substituição de diálogos internos destrutivos por construtivos e empregando a percepção emocional como o raciocínio sobre as emoções.

Identificar emoções em terceiros é uma tarefa mais exigente e $63 \%$ dos entrevistados podem identificar o ambiente emocional de quem está ao seu redor. A grande maioria, $88 \%$, acredita que expressar as emoções de forma adequada vai facilitar para que o outro aja corretamente. Isso indica que aquele emocionalmente fraco se comporte em ambiente acolhedor de soluções vindas de algum companheiro. Essa porcentagem é aumentada para $89 \%$, quando é questionada a capacidade dos líderes. Além disso, o corpo discente acredita que os líderes envolvidos no processo devem buscar a capacidade de identificar as emoções em seus liderados. ,spor.sá

Dentro da universidade, um grupo pequeno, $26 \%$, conhece pessoas com a característica de identificar emoções e contribuir com o próximo de forma adequada. Aqui surge uma necessidade de maior investigação nos estudos da emoção para líderes, para que estes possam ter direcionamento na solução de ambientes emocionalmente fracos. Necessidade essa que também é percebida não só com relação aos líderes como no tocante ao objeto de investigação inteligência emocional, de forma geral, como ressaltam Silva e Silva (2018) ao afirmar que "a pesquisa científica a nível nacional, nesse contexto é escassa...em revista nas bases de dados INDEX PSI, LILACS, PEPSIC e SCIELO, tendo encontrado 37 publicações".

Em relação ao rendimento acadêmico, é quase unânime que tal rendimento é afetado pelas questões emocionais. Um discente abalado emocionalmente tende a não ter aproveitamento satisfatório, uma vez que a sua capacidade de aprendizado pode estar afetada por suas emoções. Uma pessoa que está em situação confortável emocionalmente tende a 
ter entusiasmo e motivação para os estudos e, por conseguinte, seu rendimento poderá ser elevado, pois se concordarmos com Mayer e Salovey (1997), citados por Franco e Santos (2015), são as emoções que tornam o pensamento mais inteligente e é ela que faz pensar as emoções, levando a um equilíbrio dessa relação binomial, gerindo aquelas positivas, e negativas sem prejudicar o aprendizado.

Pode-se dizer que, a cada dez discentes, sete gostariam que seus líderes identificassem suas emoções. O líder que identifica alguém emocionado tem a oportunidade de contribuir satisfatoriamente com o liderado, de forma a preservar e fortalecer o grupo. A porcentagem é reduzida para $62 \%$, quando questionado sobre a comunicação do líder. Embora grande parte deseje que o líder identifique a sua emoção, há aqueles que não gostariam que o tema seja objeto de conversa com o líder.

Hersey e Blanchard (1986) postulam que os líderes eficazes são capazes de adaptar seu estilo de comportamento de líder às necessidades dos liderados e à situação, sendo estas não constantes, o uso do estilo apropriado de comportamento de líder constitui um desafio para cada líder eficaz. Dessa forma, independentemente dos anseios dos discentes, percebe-se que o líder deve moldar seu estilo ao ambiente emocional, uma vez que se encontre procurando soluções viáveis para o melhoramento acadêmico, ressaltando assim a importância da percepção emocional no que diz respeito a ler as mensagens não verbais enviadas pelos outros, em especial os discentes, fato que instiga uma preparação dos líderes nesse viés, o que levaria a entender seus aspectos emocionais e detalhar melhor o significado de cada mensagem, como destacam Sena et al. (2018).

Quando perguntado se a interferência adequada do líder vai afetar o rendimento acadêmico, quase todos acreditam no papel do bom líder para dar direcionamento ao melhoramento, ou seja, nessa transição para o ambiente acadêmico consideram, como o fazem Tomás et al. (2014), haver uma necessidade de enfrentamento dos desafios emocionais desenvolvendo novas estruturas de funcionamento pessoal e interpessoal, o que perpassa relações positivas com os pares e docentes.

O líder deve ser comunicativo, para que a instituição gere os melhores resultados, uma vez que:

\begin{abstract}
A comunicação é um fato nas organizações, ou seja, não existe nenhuma organização sem uma prática comunicativa, ainda que os processos comunicativos não sejam institucionalizados. Eles são essenciais para a operação da entidade e estão intimamente vinculados às formas de significar, valorar e expressar uma organização, isto é, ao processo comunicacional e constitutivo da cultura da organização, e de sua identidade, configurando imagens reconhecidas por seus diversos públicos internos e externos. A comunicação pode ser entendida, então, como um alicerce que dá forma à organização, fazendo-a ser aquilo que ela é (CARDOSO, 2006, p. 1.132).
\end{abstract}

Essa comunicação sobre a emoção é extremamente importante, visto que baixos rendimentos estão ligados à falta de comunicação entre líderes e liderados. Para Mello e Freitas (2018), é possível observar a relevância dos aspectos humanos em relação ao processo de comunicação. O líder possui o papel de mobilizar os colaboradores em busca do alcance dos objetivos organizacionais, influenciando-os em busca de melhores desempenhos indi- 
viduais e coletivos. Dessa forma, a postura adotada pelo líder pode influenciar o comportamento dos colaboradores, estimulando-os ou não a expressar suas opiniões e participar ativamente do processo de comunicação.

Esta pesquisa chama atenção, em especial, pelas respostas da sétima e décima pergunta. Os discentes consideram que as suas emoções dificultam o rendimento e acreditam que uma solução é via liderança. O controle das emoções é extremante importante para uma aprendizagem satisfatória. Em cursos com elevados índices de retenção e evasão, não é difícil encontrar discentes em situações de fraqueza emocional, seja pela falta de vaga para cursar determinado componente curricular ou pelo baixo rendimento em uma avaliação. Diante de queixas emocionais, por diversos motivos, o bom líder deve desprender-se de conteúdos curriculares e desenvolver um senso de apoio mútuo ao público discente que se encontra em situação desfavorável ao acompanhamento do curso.

Alguns comentários apontam os transtornos de ansiedade como causa de suas emoções abaladas e que isso desencadeia outros aspectos. Há falas que criticam o sistema de avaliação que não leva em conta as questões emocionais, justificando que o rendimento é afetado pelas emoções, uma vez que a tensão cai toda sobre o discente. Fato este que ressalta a importância da percepção emocional por parte do docente, já que permitiria possivelmente reconhecer e canalizar as emoções de forma equilibrada, desde um alto nível de estresse à saudades de casa, tentando engajá-los em atividades extracurriculares ou incentivando o compromisso com a persistência, como já dito.

Há discentes que julgam a comunicação do líder um bom recurso para melhorar o ambiente emocional e que a pressão imposta leva à desmotivação e até a desistência. Isso mostra a necessidade de ações que destaquem na transição para o ensino superior a existência de emoções tidas como negativas, que são inevitáveis frente a um desenvolvimento cognitivo e que busquem a percepção do discente sobre a relação das emoções com o rendimento acadêmico com a finalidade de regulá-las por meio de reações emocionais coerentes e de maneira adaptada à situação, já que:

\footnotetext{
Mesmo que inicialmente motivado para aprender, um aluno terá ainda, eventualmente, que desenvolver a autorregulação de suas emoções negativas. Embora alguns já o consigam, dificilmente pode-se esperar que todos os alunos disponham de conhecimento tanto declarativo como procedimental e condicional das estratégias de autorregulação das diversas emoções negativas (BZUNECK, 2018, p. 1.070).
}

Alguns discentes destacaram a importância do assunto e que isso deveria ser melhor debatido entre os sujeitos. E isso enfatiza ainda mais a necessidade de investigação nessa área, podendo, como Bzuneck (2018), levantar maneiras de ajudar os discentes a trabalharem a autorregulação das emoções, sejam elas negativas ou não, atentando para situações mais restritas como tédio e ansiedade, por exemplo.

Dessa forma, percebe-se um anseio acadêmico por intervenção de um líder capacitado com a habilidade de percepção emocional, dominando a leitura de mensagens não verbais e tendo empatia com a transição pela qual passam os discentes, ao saírem do Ensino Médio e ingressarem em uma universidade, que pode ser desde um alto nível de estresse à saudades 
de casa. Assim, os caminhos do sucesso estão associados ao aspecto emocional que cada um pode apresentar em cada etapa. Saber identificar e compreender as emoções são atividades cruciais no processo.

\section{CONSIDERAÇões FINAIS}

Diante do exposto, pode-se perceber que os discentes, em sua maioria, conseguem identificar suas próprias emoções, bem como, verificar problemas e soluções. É bastante claro que o ambiente abalado prejudica o rendimento acadêmico e possíveis soluções são por meio da capacitação e comunicação dos líderes envolvidos. Então, faz-se necessário uma reflexão de liderança com olhar voltado para o discente, em especial aqueles que estão em situação emocional vulnerável.

A presente pesquisa mostrou estatisticamente que o público enfrenta problemas de evasão e retenção nos componentes curriculares e isso agrava o emocional que já vem frágil durante as pressões acadêmicas e pessoais. Fica perceptível o anseio por uma comunicação adequada do líder para o melhoramento acadêmico e se espera um maior envolvimento da comunidade para que o ambiente emocional seja forte e resistente às intempéries da carreira.

Além disso, vê-se a necessidade de mais pesquisas, no que se refere às ações para se trabalhar a percepção emocional com a finalidade de regulação, respeitando as diferenças entre os discentes e destacando tal envolvimento da comunidade, como ressaltado pelos mesmos. Assim, se permitirá que além de conhecerem suas emoções, adaptando-se para um melhoramento do rendimento acadêmico, possam contar com a parceria comunicativa dos líderes envolvidos e capacitados para esse fim, já que:

\footnotetext{
A educação é um sistema, como tal precisa considerar como parte desse sistema os fatores que influem na qualidade do ensino, como a motivação de alunos, servidores, professores e gestores, a excelência de qualidade de equipamentos e infra-estrutura. Assim, é indispensável buscar mecanismos para a motivação e poder chegar a excelência na prestação dos serviços de educação (SAMPAIO, 2014, p. 15).
}

Então, espera-se que os resultados deste trabalho contribuam para uma reflexão conjunta na universidade, gerando motivação nas pessoas com o apoio dos líderes, a fim de obter melhores resultados na formação de profissionais.

\section{REFERÊNCIAS}

BZUNECK, José Aloyseo. A motivação do aluno: Aspectos introdutórios. In: Boruchovitch, Evely; BZUNECK, José Aloyseo (Org.), A motivação do aluno: Contribuições da psicologia contemporânea (p. 9-36). Petrópolis: Vozes, 2009. 
BZUNECK, José Aloyseo. Emoções acadêmicas, autorregulação e seu impacto sobre motivação e aprendizagem. ETD-Educação Temática Digital, Campinas, v. 20, n. 4, p. 1.0591.075, out./dez. 2018.

CARDOSO, Onésimo de Oliveira. Comunicação empresarial versus comunicação organizacional: novos desafios teóricos. RAP-Revista de Administração Pública, Rio de Janeiro, v. 40, n. 6, p. 1.123-44, nov./dez. 2006.

CARVALHO, Hélio Gomes; BERTOL, Artur Antonio; ALBERTON, Luiz. Liderança e motivação para a qualidade em Instituições de ensino superior públicas. In: ELETRÔNICOS DO ENCONTRO NACIONAL DE ENGENHARIA DE PRODUÇÃO, XVIII, 1998, Niterói. Anais [...]. Niterói: UFF, 1998.

CASSIMIRO, Shirley Gomes; FONTELES, Auridete Lima; FARIAS, Geazi Alves de. A liderança no contexto das organizações: um estudo da percepção dos gestores da Colaço Martins Construções e Empreendimentos Ltda no Município de Beberibe/CE. In: CONGRESSO ONLINE-ADMINISTRAÇÃO, X, 2013, Convibra. Disponível em: http://www. convibra.com.br/upload/paper/2013/34/2013_34_7369.pdf. Acessado em: 1º de abr. 2019.

CHIAVENATO, Idalberto. Gerenciando com Pessoas: Transformando o executivo em um excelente gestor de pessoas. Rio de Janeiro: Elsevier, 2005.

FRANCO, Maria da Glória Salazar d' Eça Costa; SANTOS, Natalie de Nóbrega dos. Desenvolvimento da compreensão emocional. Psicologia: Teoria e Pesquisa, Brasília, v. 31, n. 3, p. 339-348, jul./set. 2015.

HERSEY, Paul; BLANCHARD, Kenneth H. Psicologia para administradores: a teoria e as técnicas da liderança situacional, 4. ed. São Paulo: E.P.U. Editora Pedagógica e Universitária Ltda., p. 185- 214, 1986.

LAMEIRAS, Emannuel Onofre Serra. Liderança e motivação dos colaboradores: Um ensaio no sector da saúde, 2010. Dissertação (Mestrado em Gestão dos Serviços de Saúde) -Universidade de Trás-os-Montes e Alto Douro, Vila Real, 2010. Disponível em: http:// repositorio.utad.pt/bitstream/10348/599/1/msc_eoslameiras.pdf. Acessado em: $1^{\circ}$. de abr. 2019.

MELLO, Roger Goulart. FREITAS, Patrícia Gonçalves. Impactos da Liderança Sobre o Processo de Comunicação nas Organizações. Revista Científica Multidisciplinar Núcleo do Conhecimento, São Paulo, v. 6, n. 12, p. 17-27, dez. 2018.

MIGUEL, Fabiano Koich; da Silva FINOTO, Bruno Aurélio; MIRAS, Bárbara Dias. Percepção emocional e traços de personalidade: Estudo de validade divergente. ENCONTRO: Revista de Psicologia, Londrina, v. 16, n. 24, p. 107-120, jul. 2013. 
SAMPAIO, Kleber Rocha. A gestão da qualidade nas instituições de ensino superior. Faculdade Cearense em Revista, Fortaleza, v. 8, n. 2, jul./dez. 2014.

SENA, Geovana Barroso da et al. Relações entre habilidade de percepção emocional e aceitação e rejeição social em universitários. Revista Sul Americana de Psicologia, v. 6, n. 1, p. 84-100, jan./jul. 2018.

SILVA, Marcio Moreira da; SILVA, Adriana Maria Simião da. Inteligência emocional e sua aplicação no contexto educacional. LUMINAR-Revista de Ciências e Humanidades, Crato, v. 1, n. 2, p. 16-31, 2018.

SOUZA, Ana Carla Marostica de et al. Motivação para aprender em adolescentes do Ensino Médio de uma escola pública militar. PSICO, Porto Alegre, v. 50, n. 1, p. 1-8, 2019.

TOMÁS, Rita Antunes et al. Adaptação Pessoal e Emocional em Contexto Universitário: O Contributo da Personalidade, Suporte Social e Inteligência Emocional. Revista Portuguesa De Pedagogia, v. 48, n. 2, p. 87-107, jul./dez. 2014.

\section{DADOS DOS AUTORES:}

\section{Otávio Paulino Lavor}

Doutor em Engenharia Elétrica. Professor Adjunto na Universidade Federal Rural do Semi-árido. Pau dos Ferros/RN-Brasil. otavio.lavor@ufersa.edu.br

\section{Mônica Paula de Sousa Martins}

Mestre em Matemática. Professora Assistente na Universidade Federal Rural do Semi-árido. Pau dos Ferros/RN-Brasil.monica.sousa@ufersa.edu.br

Submetido em: 2-4-2019

Aceito em: $28-3-2020$ 